\title{
THE RESULTS OF EARLY AND DELAYED INTERNAL FIXATION OF FRACTURES OF THE SHAFT OF THE FEMUR
}

\author{
J. E. M. SMith, Birmingham, ENGLAND
}

From the Birmingham Accident Hospital

In the treatment of complicated fractures of the shaft of the femur internal fixation has in recent years played an increasingly useful part and has greatly improved the results. There has, however, been an increased incidence of delayed union and non-union following internal fixation, and the purpose of the present paper is to show how these may be reduced.

This review covers a ten-year period from 1953 to 1962 during which 221 fractures were treated by internal fixation. One patient died of a head injury four days after operation, and seven patients aged between seventy-four and ninety years died before union of the fracture was determined. Follow-up was incomplete in two other cases, leaving 211 fractures for study. Pathological fractures, trochanteric and supracondylar fractures, and fractures of the femur in children have been excluded. Conservative treatment was used for many uncomplicated fractures. A comparable series treated conservatively is not available because internal fixation was used only for the more severe fractures.

Assessment of union-The time of union was determined mainly on radiological evidence. Union was regarded as having occurred when the fracture was seen to be bridged by bone, and full weight bearing was possible without protection of the limb; the pronouncement of union was confirmed by the subsequent satisfactory progress of the fracture. In assessing the time of union it has been customary to err on the side of safety rather than risk submitting the limb to unprotected weight bearing too early.

Primary union is defined as that occurring within six months. The term delayed union is applied to fractures uniting between six months and two years after injury. Non-union is defined as failure of bony union two or more years after injury; as fractures which needed other operations such as bone grafting, renailing or replating; or those which re-fractured through the site of the original break after removal of the nail.

Most of the operations were done under similar conditions in one hospital by the same group of surgeons. Medullary fixation with a Küntscher nail usually afforded the best fixation with a minimum of stripping of periosteum and this method was used in the majority of cases. A few fractures, particularly at the junction of the middle and lowest thirds, were treated by plating. Plating required more extensive exposures and more stripping of the soft tissues: the incidence of non-union was higher and these results have therefore been assessed separately.

TABLE I

The Causes of the Injuries

\begin{tabular}{|c|c|c|}
\hline Cause of injury & Early operation & Delayed operation \\
\hline Traffic accidents & 53 & 85 \\
\hline Falls & 29 & 32 \\
\hline Others & 3 & 9 \\
\hline
\end{tabular}

Particular attention has been paid to the timing of operation. It was shown by Smith (1959) in fractures of the shafts of the radius and ulna that when internal fixation was delayed, the incidence of delayed union and of non-union was reduced. These findings were supported by those of Charnley and Guindy (1961) in a study of femoral shaft fractures. 
The present series has been further subdivided according to the time of operation. Early fixation is defined as that done within the first six days after injury and delayed fixation as that done after the first week. The majority of delayed fixations were done in the second and third weeks though a few were done later. Fractures fixed after the eighth week are not included in this review.

After operation the limbs were supported in Thomas's splints for periods of up to twelve weeks. Weight bearing was not allowed until union was well advanced. The causes of the injuries, the ages, and the levels of fracture are shown in Tables I, II and III.

TABLE II

The Ages of the Patients

\begin{tabular}{|c|c|c|}
\hline Age (years) & Early operation & Delayed operation \\
\hline $15-19$ & 12 & 28 \\
\hline $20-29$ & 28 & 42 \\
\hline $30-39$ & 11 & 11 \\
\hline $40-49$ & 8 & 11 \\
\hline $50-59$ & 8 & 8 \\
\hline $60-69$ & 7 & 4 \\
\hline $70-79$ & 5 & 16 \\
\hline $80-89$ & 5 & 5 \\
\hline $90-99$ & 1 & 1 \\
\hline
\end{tabular}

TABLE III

The LeVel of the Fractures

\begin{tabular}{|c|c|c|}
\hline Level of fracture & Early operation & Delayed operation \\
\hline Middle and uppermost thirds & 28 & 36 \\
\hline Mid-shaft & 42 & 67 \\
\hline Middle and lowest thirds & 12 & 20 \\
\hline Double fracture . & 3 & 3 \\
\hline
\end{tabular}

\section{RESULTS}

These are given in four groups (Table IV) showing the results obtained from plating and medullary nailing in closed and compound fractures. Of the fractures in Group I treated by early operation, which in these cases amounted to plating on the day of injury, non-union occurred in four of the five fractures, and in the other one union was delayed. Although the numbers are small they suggest a high non-union rate. In the same group are shown the results of four compound fractures of the femur which were treated by delayed plating about two to three weeks after injury. Although the numbers again are small, primary union was obtained in every case. Plating, however, is not to be recommended as the extensive exposure and muscle stripping which is needed often delays the recovery of knee movement. There is a strong case for treating fractures at the junction of the middle and lowest thirds of the femur conservatively, but it must be remembered that when there is a compound wound with gross 
displacement and severe soft-tissue damage, the results of conservative treatment may be unsatisfactory. In such cases delayed internal fixation, using a medullary nail if possible, reduces the risk of delayed union and may ultimately secure a better range of knee movement.

In Group II the fractures were obviously less severe than those in Group I and the numbers are again small. It is significant that in the fractures treated by early plating primary union was obtained in one case; delayed union in another; and non-union occurred in the remaining case.

In twelve closed fractures treated by delayed plating non-union occurred once. This fracture calls for special mention, being the only instance in this series where non-union followed delayed fixation. The patient was a man of twenty-three who sustained a closed transverse fracture of the mid-shaft in a motor-cycle accident. The fracture was fixed eleven days after injury; a six-hole plate was applied but only four screws were inserted. Had medullary fixation been used it is possible that in this series there would not have been a case of non-union to report.

TABLE IV

Results of Early and Delayed Internal Fixation in 211 Fractures

\begin{tabular}{|c|c|c|c|c|c|c|c|c|}
\hline & \multicolumn{4}{|c|}{ Early operation (0-6 days) } & \multicolumn{4}{|c|}{ Delayed operation (after 7 days) } \\
\hline & Number & $\begin{array}{c}\text { Primary } \\
\text { union }\end{array}$ & $\begin{array}{c}\text { Delayed } \\
\text { union }\end{array}$ & Non-union & Number & $\begin{array}{c}\text { Primary } \\
\text { union }\end{array}$ & $\begin{array}{c}\text { Delayed } \\
\text { union }\end{array}$ & Non-union \\
\hline $\begin{array}{l}\text { Group I } \\
\text { Compound fractures treated } \\
\text { by plating }\end{array}$ & 5 & 0 & 1 & 4 & 4 & 4 & 0 & 0 \\
\hline $\begin{array}{l}\text { Group II } \\
\text { Closed fractures treated by } \\
\text { plating }\end{array}$ & 3 & 1 & 1 & 1 & 12 & 9 & 2 & 1 \\
\hline $\begin{array}{l}\text { Group III } \\
\text { Compound fractures treated } \\
\text { by medullary nailing. }\end{array}$ & 20 & 9 & 5 & 6 & 15 & 8 & 7 & 0 \\
\hline $\begin{array}{l}\text { Group IV } \\
\text { Closed fractures treated by } \\
\text { medullary nailing }\end{array}$ & 57 & 30 & 18 & 9 & 95 & 81 & 14 & 0 \\
\hline Totals . & 85 & 40 & 25 & 20 & 126 & 102 & 23 & 1 \\
\hline
\end{tabular}

In Groups III and IV medullary nailing was done and the benefits of delayed fixation are clearly shown. Of 110 fractures there was not a single case of non-union. The majority of these fractures were severe; fifteen were compound, and many of the closed injuries showed gross swelling and wide displacement of the bone ends.

In the same groups the non-union rate with early nailing was 30 per cent for compound fractures and 16 per cent for closed ones. A significant finding is that compound fractures treated by delayed fixation gave better results than closed fractures treated by early fixation.

The most important finding is a non-union rate of 0.8 per cent in 126 fractures treated by delayed internal fixation. These figures correspond closely with those obtained in fractures of the radius and ulna (Smith 1959) and in those of the femur (Charnley and Guindy 1961).

\section{DISCUSSION}

On the clinical and radiological evidence available, internal fixation between seven to twenty-one days after injury, a phase when repair is very active, serves as a powerful stimulus to repair of the fracture, sometimes with abundant callus. Analysis of cases of delayed union 
and non-union following early internal fixation shows that these complications are most likely to result when operation is carried out on the day of injury; the risk is less on the second and third days, and still less from four to six days after injury. The importance of recognising this is that, in centres where the majority of operations are done between the fourth and fourteenth days, observers may fail to detect a significant difference between the results of early and delayed fixation. To be convinced of these complications after early fixation of femoral shaft fractures it is essential to examine the results of operation done during the first three days and particularly those done on the day of injury.

The practical advantages of a policy of delayed fixation are considerable. A fracture of the femur is a severe injury with internal blood loss that may amount to two or more litres. Blood loss from other injuries is often associated and presents a major problem in resuscitation. The initial surgery should therefore consist of meticulous wound excision and closure, followed by the application of efficient splintage and traction. To delay internal fixation makes treatment safer.

Fractures of the shaft of the femur are suitable for delayed operation. The length of the limb can be maintained by traction, though distraction must be avoided, and to operate some two weeks after injury is not more difficult. Subsidence of the initial swelling reduces the length of the incision required and with good relaxation reduction is easily obtained.

It must be emphasised that if the best response is to be obtained internal fixation should not be delayed more than three weeks. The optimum time for operation is probably between the tenth and fourteenth days.

If operation has to be done after the sixth week it may be wise after nailing to apply strips of cancellous iliac bone round the fracture as union in such cases may otherwise be slow. The aim must be to anticipate delayed union and to nail the fracture at the optimum time. It is also important not to expect rapid union with profuse periosteal callus in all cases. Associated head injury or the possibility of fat embolism are two additional reasons for avoiding operation within the first few days.

Generally speaking, the worse the prognosis of the fracture the less likely is rapid union with profuse callus to occur, but it is in these cases particularly that delayed internal fixation is indicated. However unimpressive the initial response after delayed fixation may be, union of the fracture within a reasonable time can be confidently expected in almost every case.

\section{SUMMARY}

1. The results in 211 fractures of the shaft of the femur in adults treated by internal fixation have been reviewed.

2. A comparison has been made between the effects of early internal fixation within the first six days of injury and delayed fixation.

3. Eighty-five fractures treated by early fixation gave a rate of non-union of 23 per cent; in 126 fractures treated by delayed fixation the rate was $0 \cdot 8$ per cent.

4. Delayed operation is therefore advocated for the majority of femoral shaft fractures for which internal fixation is indicated.

I would like to record my gratitude to the surgeons of the Birmingham Accident Hospital: Professor William Gissane, Mr F. G. Badger, Mr J. H. Hicks, Mr D. M. Jackson, Mr P. S. London, Mr H. Proctor and Mr J. S. Cason for allowing me to review their patients.

\section{REFERENCES}

Charnley, J., and Guindy, A. (1961): Delayed Operation in the Open Reduction of Fractures of Long Bones. Journal of Bone and Joint Surgery, 43-B, 664.

SмIтH, J. E. M. (1959): Internal Fixation in the Treatment of Fractures of the Shafts of the Radius and Ulna in Adults. Journal of Bone and Joint Surgery, 41-B, 122.

VOL. 46 B, NO. 1, FEBRUARY 1964 